\title{
Patient Perceptions of Telehealth Primary Care Video Visits
}

Rhea E. Powell, MD MPH'1,3

Jeffrey M. Henstenburg, $B S^{2}$

Grace Cooper, BA ${ }^{2}$

Judd E. Hollander, $M D^{2,3}$

Kristin L. Rising, MD, MSHP2,3

'Department of Medicine, Thomas Jefferson University, Philadelphia, Pennsylvania

${ }^{2}$ Department of Emergency Medicine, Thomas Jefferson University, Philadelphia, Pennsylvania

${ }^{3}$ National Academic Center for Telehealth, Thomas Jefferson University, Philadelphia, Pennsylvania

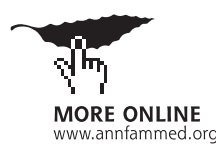

Conflicts of interest: authors report none.

\section{CORRESPONDING AUTHOR}

Kristin L. Rising, MD, MSHP

Department of Emergency Medicine

Sidney Kimmel Medical College at Thomas

Jefferson University

1025 Walnut St, Suite 300

Philadelphia, PA 19107

Kristin.rising@jefferson.edu

\begin{abstract}
PURPOSE Telehealth is a care delivery model that promises to increase the flexibility and reach of health services. Our objective is to describe patient experiences with video visits performed with their established primary care clinicians.
\end{abstract}

METHODS We constructed semistructured, in-depth qualitative interviews with adult patients following video visits with their primary care clinicians at a single academic medical center. Data were analyzed with a content analysis approach.

RESULTS: Of 32 eligible patients, 19 were successfully interviewed. All patients reported overall satisfaction with video visits, with the majority interested in continuing to use video visits as an alternative to in-person visits. The primary benefits cited were convenience and decreased costs. Some patients felt more comfortable with video visits than office visits and expressed a preference for receiving future serious news via video visit, because they could be in their own supportive environment. Primary concerns with video visits were privacy, including the potential for work colleagues to overhear conversations, and questions about the ability of the clinician to perform an adequate physical examination.

CONCLUSIONS Primary care video visits are acceptable in a variety of situations. Patients identified convenience, efficiency, communication, privacy, and comfort as domains that are potentially important to consider when assessing video visits vs in-person encounters. Future studies should explore which patients and conditions are best suited for video visits.

Ann Fam Med 2017;15:225-229. https://doi.org/10.1370/afm.2095.

\section{INTRODUCTION}

$\mathrm{T}$ elemedicine, or telehealth, includes telecommunication via a variety of platforms designed to enhance patient-centered health care. ${ }^{1-3}$ Telehealth in its many forms offers conveniences including increased care accessibility, decreased transportation barriers, and patient empowerment. ${ }^{4-8}$ Studies of video visits have demonstrated these benefits in specialty settings including wound care, prenatal genetic screening, family planning, cardiovascular care, and home care. ${ }^{9-15}$ One study of patient experiences with video visits in rural areas found that they were associated with decreased travel costs and lost time/wages, increased access to social support, and better ability to tailor care delivery to patient and family needs. ${ }^{16}$

Because of these benefits, video visits are being adopted in a variety of settings. Uptake in the United States has occurred most rapidly where reimbursement is favorable. Medicare reimburses for video visits in health professional shortage areas and for specific approved services. ${ }^{17}$ As a result, much knowledge about patient experiences with video visits is limited to specific disease-related applications and to use in rural settings. ${ }^{18-20}$

Video visits are increasingly used in other settings, including primary care, but there are limited data on patient experiences with primary care video visits. One study tested video visits with patients communicating via webcam with their primary care physician while sitting in an adjacent room, followed immediately by an in-person visit. Patients reported video visits acceptable, but less satisfactory, than in-person visits. ${ }^{21}$ While such test scenarios provide useful information about the feasibility and accept- 
ability of video visits for primary care, understanding optimal use requires exploring real-world patient experiences.

We report results of a qualitative study of patient experiences with video visits with their established primary care clinicians and their preferences for future use of video visits.

\section{METHODS}

\section{Intervention}

JeffConnect, an initiative launched at Thomas Jefferson University in 2015, was used to make primary care video visits available. During the initial implementation period, primary care clinicians identified patients to pilot video visits. The video visits were offered without cost to encourage participation. No specific patient eligibility criteria were suggested ${ }_{i}$ rather providers were asked to offer the service to anyone for whom there was no definitive need for in-person visit.

A member of the care team or a telehealth coordinator approached patients to assess interest in participating in a video visit. A telehealth coordinator trained in the use of the video-conferencing platform facilitated the scheduling and provided patient education, including instruction on downloading the application to a smartphone or tablet or accessing the JeffConnect platform (http://www.jeffconnect.org) on the computer.

\section{Study Design and Setting}

We conducted individual semistructured interviews with patients who had completed a video visit with their primary care physician at either the family medicine or the internal medicine practice at Thomas Jefferson University.

\section{Sample}

All patients 18 years old or older who had a video visit with their existing primary care physician were eligible for inclusion. The study was approved by the Thomas Jefferson University institutional review board.

\section{Data Collection and Management}

At the end of each video visit, the clinician alerted his or her patient that a research assistant might call to ask about the experience. The research team was notified weekly of all completed video visits, and a team member attempted to contact each patient within 1 week of the visit. Two members of the research team (J.M.H. and G.C.), both trained in qualitative interview techniques before the study began, conducted the interviews. They obtained verbal consent from interested patients and interviewed them by phone. The study principal investigator (K.R.), who has masters-level training in qualitative methodology, was responsible for training and monitoring research team activity.

The interview guide included open-ended questions to elicit patients' experience with their video visits and impressions of the technology's potential to address health care needs. Questions covered personal experience with video calls, technical issues with the visit, emotional experience during the visit, and future uses for video visits. (The interview guide is available in a Supplemental Appendix at http://www. annfammed.org/content/15/3/225/suppl/DC1). Questions were piloted on the patients enrolled earliest, and we revised or eliminated unclear questions. Interviews were audio-recorded to allow accurate transcription.

Patients completed a demographic survey that asked for date of birth, race, gender, physical location during the video visit (ie, work or home), insurance status, education level, employment status, yearly household income, medical conditions, access to pertinent technology, and prior use of video calling technology.

\section{Analysis}

Interviews were transcribed, stripped of identifying information, and imported into NVivo $10^{22}$ for coding and analysis. Two members of the research team (K.R., R.P.) coded the data using a conventional content analysis approach, with the purpose of classifying interview text into distinct categories representing similar meanings. ${ }^{23}$ This approach allowed categories to emerge from the data instead of applying preconceived categories. Both coders read 2 transcripts to gain a general understanding of the interview content, then re-read them to identify key words that captured prominent concepts related to patient experiences. The coders met to discuss the identified concepts and create an initial code structure. The codes were applied to subsequent interviews and refined to include new themes as they appeared. This process was repeated until the coders agreed upon a final coding structure, with discrepancies resolved through consensus. The final structure was applied to all the transcripts, with double coding of $25 \%$ of them. The coders maintained a decision tree throughout analysis to document key decisions made. Descriptive statistics were used to characterize the study population.

\section{RESULTS}

Thirty-two patients were eligible to participate. Twenty-one (66\%) were successfully contacted, and all consented to be interviewed. Two interview recordings failed, leaving 19 interviews for analysis (Table 1). The median age was 43 years (range $23-94$ ); $53 \%$ of patients were male, and $42 \%$ were black. The majority 
reported having used video calls for personal use, commonly with smartphones (74\%). None had experience with video calls for health care. More than two-thirds $(68 \%)$ were at home during their visit. One interviewee was a family member caregiver. Visit reasons included chronic disease management, follow-up of a recent acute issue, a new acute issue, and review of lab results.

\begin{tabular}{|c|c|}
\hline Characteristic & Value \\
\hline Age, mean (range), y & $43(23-94)$ \\
\hline Female, $\mathrm{n}(\%)$ & $9(47)$ \\
\hline Hispanic, n (\%) & $1(5)$ \\
\hline \multicolumn{2}{|l|}{ Race, n (\%) } \\
\hline Black & $8(42)$ \\
\hline White & $9(47)$ \\
\hline Other & $2(11)$ \\
\hline \multicolumn{2}{|l|}{ Location during visit, $\mathrm{n}(\%)$} \\
\hline Home & $13(68)$ \\
\hline Office & $6(32)$ \\
\hline \multicolumn{2}{|l|}{ Insurance, n (\%) } \\
\hline HMO/PPO/Private & $12(63)$ \\
\hline Medicaid & $1(5)$ \\
\hline Medicare & $3(16)$ \\
\hline Medicare/Other & $2(11)$ \\
\hline Unknown & $1(5)$ \\
\hline \multicolumn{2}{|l|}{ Education, n (\%) } \\
\hline High school / GED / Some college & $5(26)$ \\
\hline College & $6(32)$ \\
\hline Postgraduate degree & $8(42)$ \\
\hline \multicolumn{2}{|l|}{ Employment status, n (\%) } \\
\hline Employed & $13(68)$ \\
\hline Retired & $1(5)$ \\
\hline Student & $1(5)$ \\
\hline Disabled & $1(5)$ \\
\hline Unemployed & $3(16)$ \\
\hline \multicolumn{2}{|l|}{ Household income (yearly), n (\%) } \\
\hline$<\$ 10,000$ & $1(5)$ \\
\hline$\$ 10,000-24,999$ & $2(11)$ \\
\hline$\$ 25,000-49,999$ & $4(21)$ \\
\hline$\$ 50,000-99,999$ & $6(32)$ \\
\hline$\$ 100,000$ & $4(21)$ \\
\hline Unknown & $2(11)$ \\
\hline \multicolumn{2}{|l|}{ Available technology, $\mathrm{n}(\%)$} \\
\hline Computer with video camera & $18(95)$ \\
\hline Smartphone & $14(74)$ \\
\hline Tablet & $12(63)$ \\
\hline \multicolumn{2}{|l|}{ Devices used for past video calls, $\mathrm{n}(\%)$} \\
\hline Computer with video camera & $12(63)$ \\
\hline Smartphone & $14(74)$ \\
\hline Tablet & $6(32)$ \\
\hline \multicolumn{2}{|l|}{ Reason for video visit, $\mathrm{n}(\%)$} \\
\hline Chronic disease management & $9(47)$ \\
\hline Short-term follow-up of recent acute issue & $7(37)$ \\
\hline Review of lab results & $2(11)$ \\
\hline New acute issue & $1(5)$ \\
\hline
\end{tabular}

The mean time between telehealth visit and interview was 9 days (range 0-31 days).

\section{Technological Aspects of the Experience}

Several study participants found the connection process easy, while others reported technical challenges such as problems with visit codes or passwords. Some received help from telehealth coordinators or their physicians, and 1 reported assistance from family. Once connected, most participants reported either no issues or minor technical issues. Four participants reported a lag between video and audio, 1 reported blurry images, and another reported audio feedback. Three participants reported moderate technical issues due to Internet connection problems.

\section{Perceptions of Video Visits}

Most participants reported a positive experience with video visits, citing conveniences of not having to miss work, travel, or change attire. One patient explained, "You're sitting right in your room on your computer. How much more convenient can that be? And you don't even have to take a shower. I mean you can get on the computer, talk to the doctor, go back to bed." Participants also noted decreased wait times compared to in-office visits, though 1 would have preferred having the doctor initiate the visit to further reduce waiting. The caregiver-family member remarked on the ability to incorporate individuals who wouldn't have been present in an office visit. Most patients felt comfortable talking with their doctor via video; while a few noted loss of the "personal" feel of a face-to-face visit, they did not consider it a significant limitation.

For those who connected to video visits in the workplace, privacy was an important consideration. While they noted the advantage of not missing work, those without private offices struggled to find space where coworkers would not overhear. One person reported that the inability to achieve privacy at work impaired their ability to have a proper exam. A few participants suggested potential workplace privacy solutions including use of headphones and reserving office space for the visit.

\section{Comparisons of Office-Based and Video Visits}

Participants raised cost and transportation as the main considerations favoring video visits over office visits. Costs included gas, parking, co-pays, wait time, and work absenteeism. Other barriers that video visits minimized included dealing with traffic, being late to appointments, finding offices, scheduling a convenient appointment, childcare, and physical limitations. One participant noted, "I'm personally handicapped, and my left side is a little bit weak and almost paralyzed. Just 
getting to an appointment is a task for me... Going down my stairs to my computer, it's better."

\section{Future Use}

All patients voiced interest in future video visits, though for varying reasons and situations. Some preferred video visits for all needs: "It would be my go-to for anything before I actually go into the doctor's office." Others preferred video visits as a supplement to office visits, acknowledging that office visits would be needed when a physical examination might affect decision making. Participant responses were similarly varied regarding the potential impact of video visits on the use of in-person services for primary care or emergency care; some anticipated less frequent use of in-person services, and others anticipated no change.

Patients had different perspectives on whether they prefer to hear bad news in a video call. Some said they preferred it, thinking that they could get the news earlier and be in a comfortable location with supportive people. One participant explained, "If it was something earth-shattering, you could cry in your own bedroom and not have to worry, I mean driving from downtown and you're upset or what-not..." Others preferred to receive serious news in person, explaining, "If the doctor were telling me I have a fatal disease or a disease that could be fatal, and I have to go into immediate serious care, probably better in-person." Several patients stated no clear preference between the 2 options.

\section{DISCUSSION}

Our study suggests that patients may accept and even prefer video visits with established primary care clinicians. Patients feel comfortable talking with their clinicians over video call, though patient location may affect privacy. A subset of patients say they would prefer video visits for receiving serious news.

Our findings expand the knowledge base about the urban use of telehealth and support the growing consensus that incorporating telehealth into primary care will allow patients to access their usual source of care more conveniently. ${ }^{24}$ Expansion of telehealth to address episodic and chronic conditions has been identified as a significant trend in the evolution of telehealth applications. ${ }^{25} \mathrm{~A}$ recent survey found that patients who used MinuteClinic telehealth visits reported high satisfaction, identifying convenience and perceived high quality of care as contributors. ${ }^{26}$ Our work adds insight into the benefits of video visits in primary care, highlighting improved convenience, efficiency, privacy, and comfort for patients. It also raises new considerations unique to telehealth that warrant discussion with patients before use, such as using headphones or finding a private room to use during a video visit outside of the home.

Optimal approaches to delivering serious news have been explored in other disciplines, primarily in the oncology literature. Frameworks for communication of serious news encourage establishing a private setting, with family or friends nearby if desired, the implicit recommendation being that this communication occur in person. ${ }^{27}$ Yet a survey of patient opinions on communication of serious news suggested that patients value content of communication above setting. ${ }^{28}$ It has been suggested more recently that modes of remote communication like telehealth may be a good alternative and in some cases preferable to in-person communication. ${ }^{29}$ Video visits may enable more timely communication of test results than in-person appointments. Our findings suggest that some patients may prefer receiving serious news remotely via video visit for reasons of comfort, social support, and privacy.

Study participants repeatedly cited reduced costs as an important benefit of video visits. As part of this pilot program, patients were not required to pay a visit co-pay. While this likely contributed to participants' opinions of the cost benefits, patients also noted that they saved transportation costs and were absent from work for less time. Further work is needed to identify the full range of patient cost considerations related to telehealth. Cost issues have important implications for practices and health systems incorporating telehealth into care models, as they are likely to impact patient satisfaction and uptake of virtual services. ${ }^{30}$

This study has several limitations. The sampling frame was limited to patients within 2 practices in 1 health system, both successful early adopters of this service. Most participants had experience with video conferencing, and all had successful encounters, so technical problems that might shape patients' experiences with video visits (such as being unable to set up a visit or not having access to video technology) did not arise. More, we don't know how clinicians selected potential participants, and their selection criteria may have introduced bias in the population. We were unable to contact or are missing the interview data for $41 \%$ (13/32) of the individuals approached for this study, and we cannot tell how this lack may affect transportability of findings. Additionally, while efforts were made to conduct the interviews as close to the visit as possible, interviews were conducted up to 1 month later, and patients with longer interview delays may have had difficulties remembering details of their visit. In addition, 2 of the authors were involved with developing the telehealth program at the clinic, and 1 of the physician authors is in 1 of the clinical practices implementing this service. To minimize the bias this might introduce, the 
2 non-physician team members conducted all the interviews, and the group as a whole interpreted the results.

We acknowledge these limitations and recognize that this study's findings are most transferable to patients who have the technical ability and knowledge to complete these visits. Future research is needed to purposefully sample patients who have no prior experience with video technology and to solicit opinions of patients who experience challenges with connectivity.

In our study, patients accepted and in some cases even preferred telehealth primary care visits to in-office visits. Their experiences with telehealth visits for primary care were shaped by convenience, efficiency, privacy, and comfort. These findings shed light on video visit characteristics that are important to patients, and they should further the development of patient-centered outcome measures of satisfaction with telehealth encounters. Further research is needed to identify populations and visit purposes most appropriate for integrating telehealth primary care visits.

To read or post commentaries in response to this article, see it online at http://www.AnnFamMed.org/15/3/225.

Key words: telemedicine; primary health care; patient satisfaction

Submitted June 27, 2016; submitted, revised, October 14, 2016; accepted October 22, 2016.

Funding support: We acknowledge the Sidney Kimmel Medical College Summer Student Research Program for its financial support of this project.

Prior presentations: Abstract presented at Society for General Internal Medicine Annual Meeting; May 11-14, 2016; Hollywood, Florida.

Supplementary materials: Available at http://www.AnnFamMed. org/content/15/3/225/suppl/DC1/.

\section{References}

1. Gardner MR, Jenkins SM, O'Neil DA, Wood DL, Spurrier BR, Pruthi S. Perceptions of video-based appointments from the patient's home: A patient survey. Telemed J E Health. 2015;21(4):281-285.

2. Ertel AE, Kaiser T, Shah SA. Using Telehealth to Enable PatientCentered Care for Liver Transplantation. JAMA Surg. 2015;150(7): 674-675.

3. Zulman DM, Jenchura EC, Cohen DM, Lewis ET, Houston TK, Asch SM. How Can eHealth Technology Address Challenges Related to Multimorbidity? Perspectives from Patients with Multiple Chronic Conditions. J Gen Intern Med. 2015;30(8):1063-1070.

4. Menon PR, Stapleton RD, McVeigh U, Rabinowitz T. Telemedicine as a tool to provide family conferences and palliative care consultations in critically ill patients at rural health care institutions: a pilot study. Am J Hosp Palliat Care. 2015;32(4):448-453.

5. Freeman KA, Duke DC, Harris MA. Behavioral health care for adolescents with poorly controlled diabetes via Skype: does working alliance remain intact? J Diabetes Sci Technol. 2013;7(3):727-735.

6. Viers BR, Lightner DJ, Rivera ME, et al. Efficiency, satisfaction, and costs for remote video visits following radical prostatectomy: a randomized controlled trial. Eur Urol. 2015;68(4):729-735.

7. Sharareh B, Schwarzkopf R. Effectiveness of telemedical applications in postoperative follow-up after total joint arthroplasty. J Arthroplasty. 2014;29(5):918-922.e1.
8. Gund A, Sjöqvist BA, Wigert $H$, Hentz E, Lindecrantz $K$, Bry K. A randomized controlled study about the use of eHealth in the home health care of premature infants. BMC Med Inform Decis Mak. 2013;13:22.

9. Abrams DJ, Geier MR. A comparison of patient satisfaction with telehealth and on-site consultations: a pilot study for prenatal genetic counseling. J Genet Couns. 2006;15(3):199-205.

10. Clegg A, Brown T, Engels D, Griffin P, Simonds D. Telemedicine in a rural community hospital for remote wound care consultations. J Wound Ostomy Continence Nurs. 2011;38(3):301-304.

11. Grindlay K, Lane K, Grossman D. Women's and providers' experiences with medical abortion provided through telemedicine: a qualitative study. Womens Health Issues. 2013;23(2):e117-e122.

12. Dinesen B, Nøhr C, Andersen SK, Sejersen H, Toft E. Under surveillance, yet looked after: telehomecare as viewed by patients and their spouse/partners. Eur J Cardiovasc Nurs. 2008;7(3):239-246.

13. Grant LA, Rockwood T, Stennes L. Client satisfaction with telehealth services in home health care agencies. J Telemed Telecare. 2015; 21(2):88-92.

14. Eriksson L, Lindström B, Ekenberg L. Patients' experiences of telerehabilitation at home after shoulder joint replacement. J Telemed Telecare. 2011;17(1):25-30.

15. van Gurp J, van Selm M, Vissers K, van Leeuwen E, Hasselaar J. How outpatient palliative care teleconsultation facilitates empathic patient-professional relationships: a qualitative study. PLoS One. 2015;10(4):e0124387

16. Sevean P, Dampier S, Spadoni M, Strickland S, Pilatzke S. Patients and families experiences with video telehealth in rural/remote communities in Northern Canada. J Clin Nurs. 2009;18(18):2573-2579.

17. Center for Connected Health Policy. Telehealth and medicare. Center for Connected Health Policy. http://www.cchpca.org/telehealthand-medicare. Accessed Oct 15, 2016.

18. Jenkins-Guarnieri MA, Pruitt LD, Luxton DD, Johnson K. Patient perceptions of telemental health: Systematic review of direct comparisons to in-person psychotherapeutic treatments. Telemed e-Health. 2015;21(8):652-660.

19. Fatehi F, Martin-Khan M, Smith AC, Russell AW, Gray LC. Patient satisfaction with video teleconsultation in a virtual diabetes outreach clinic. Diabetes Technol Ther. 2015;17(1):43-48.

20. Buchanan AH, Datta SK, Skinner CS, et al. Randomized Trial of Telegenetics vs. In-Person Cancer Genetic Counseling: Cost, Patient Satisfaction and Attendance. J Genet Couns. 2015;24(6):961-970.

21. Dixon RF, Stahl JE. Virtual visits in a general medicine practice: a pilot study. Telemed e-Health e-health. 2008;14(6):525-530.

22. QSR International. NVivo qualitative data analysis software: Version 10. 2012.

23. Hsieh H-F, Shannon SE. Three approaches to qualitative content analysis. Qual Health Res. 2005;15(9):1277-1288.

24. Levine DM, Linder JA. Retail Clinics Shine a Harsh Light on the Failure of Primary Care Access. J Gen Intern Med. 2016;31(3):260-262.

25. Dorsey ER, Topol EJ. State of Telehealth. N Engl J Med. 2016;375(2): 154-161.

26. Polinski JM, Barker T, Gagliano N, Sussman A, Brennan TA, Shrank WH. Patients' Satisfaction with and Preference for Telehealth Visits. J Gen Intern Med. 2016;31(3):269-275.

27. Baile WF, Buckman R, Lenzi R, Glober G, Beale EA, Kudelka AP. SPIKES-A six-step protocol for delivering bad news: application to the patient with cancer. Oncologist. 2000;5(4):302-311.

28. Parker PA, Baile WF, de Moor C, Lenzi R, Kudelka AP, Cohen L. Breaking bad news about cancer: patients' preferences for communication. J Clin Oncol. 2001;19(7):2049-2056. http://www.ncbi.nlm. nih.gov/pubmed/11283138.

29. Krishnan N, Fagerlin A, Skolarus TA. Rethinking Patient-Physician Communication of Biopsy Results-The Waiting Game. JAMA Oncol. 2015;1(8):1025-1026.

30. Cusack CM, Pan E, Hook JM, Vincent A, Kaelber DC, Middleton B. The value proposition in the widespread use of telehealth. J Telemed Telecare. 2008:14(4):167-168. 